\title{
PERSPECTIVAS DA FILOSOFIA NO BRASIL DO PONTO DE VISTA DE UM SCHOLAR
}

Guido Antônio de Almeida

(UFRJ)

Quando o prof. Ivan Domingues me convidou para participar desta mesa e me pediu que falasse sobre as perspectivas da Filosofia no Brasil do ponto de vista de um scholar, não foi sem relutância que aceitei a tarefa. Primeiro, porque não me via muito bem como representante dos scholars brasileiros na área da Filosofia. Segundo, e mais importante, porque não me sentia à vontade para falar, na minha idade, sobre as perspectivas da Filosofia no Brasil. Falar sobre perspectivas não é uma simples questão de fazer previsões ou avaliar probabilidades. É falar sobre um futuro que se quer realizar ou evitar, em todo o caso sobre um futuro que projetamos e desejamos moldar a partir de nossos desejos ou temores. E isso é um assunto que é mais bem tratado, ponderei, pelos jovens, que têm à sua frente o tempo necessário para tentar moldá-lo. Aos velhos cabe antes fazer um balanço do passado. Persuadido, no entanto, a aceitar a tarefa, terei forçosamente de falar delas do ponto de vista de um velho, que rememora as perspectivas que traçava para a Filosofia no Brasil, juntamente com outros de sua geração, e que faz agora um balanço do que foi alcançado.

Para isso quero lembrar duas coisas. A primeira é o fato de que minha geração (que começou a atuar nos anos 70) foi uma geração de transição, a geração que fez a passagem entre uma época em que a Filosofia no Brasil tinha um caráter que (com honrosas exceções, é claro) poderíamos dizer amador, ou diletante, para o período em que nos encontramos agora, no qual a Filosofia tem uma face pode-se dizer bem mais profissional. Contribuiu para isso o fato de que um grande número de estudantes brasileiros, espontaneamente ou forçados pela ditadura militar instaurada no país, saiu do Brasil em busca 
de um doutorado na Europa. Era, portanto, uma geração marcada, por um lado, por um maior ou menor engajamento político, por outro, pelo desejo de uma melhor formação acadêmica na Filosofia. Isso explica, creio eu, a formação de duas tendências, ou correntes de pensamento, nessa geração após seu retorno ao Brasil. Assim, tínhamos, de um lado, aqueles que viam na Filosofia um instrumento para a crítica cultural e política dentro e fora do ambiente acadêmico e, de outro, aqueles que viam nela uma atividade estritamente acadêmica, entendida precisamente, para usar a expressão do prof. Ivan Domingues, como uma tarefa para scholars. Essa divisão culminou num congresso da ANPOF (Gramado, RS em meados dos anos 80), no qual foi eleita uma diretoria que priorizava, para desgosto dos scholars, a visão da Filosofia como uma atividade crítica engajada nos debates culturais e políticos a serem travados dentro e fora dos muros acadêmicos.

Naturalmente, essas duas perspectivas sobre a Filosofia são igualmente legítimas e não precisam ser vistas como incompatíveis e antagônicas. Na época, porém, a questão tinha uma certa carga explosiva porque ela se colocava no quadro de uma associação representativa dos programas de pós-graduação em Filosofia, de tal sorte que o que estava em questão era o rumo a dar ao estudo da Filosofia na academia, ou seja, decidir qual das duas atividades deveria ser priorizada, as atividades do scholar ou as atividades do intelectual engajado.

Felizmente, essa questão não é mais atual, e é difícil compreender sem contextualizar como ela pôde inflamar tanto os ânimos filosóficos de então. Acho, porém, que a questão acabou por se resolver a contento de todos. Primeiro porque se pode dizer com segurança, creio eu, que o estudo da Filosofia entendida como assunto para scholars está, em certo sentido, solidamente implantado em nossas universidades. Segundo porque a ninguém ocorre mais, se é que jamais ocorreu, tomar como menos importante para a Filosofia estar presente em debates fora da academia. Isso fica especialmente claro no caso de disciplinas como a ética, a Filosofia política e a estética, que sempre foram disciplinas cultivadas na academia, e cuja voz tem de ser e se faz ouvida fora da academia, quando se trata, por exemplo, de questões de justiça e de direito, de bioética, de crítica de arte ou teoria literária.

O tempo mostrou, pois, que o conflito entre os scholars, voltados para os problemas clássicos da Filosofia, e os filósofos engajados na discussão de problemas da sociedade e da cultura contemporânea, podia ser resolvido de maneira satisfatória para os dois lados. Por conseguinte, que as perspectivas que traçavam para a Filosofia não eram antagônicas, mas podiam ser perseguidas paralelamente, pois não ocorreu o que dois lados temiam, a saber, nem a 
politização dos Departamentos de Filosofia nem o alheamento da Filosofia aos problemas da vida real.

O segundo ponto que desejo recordar é a consequência tirada pelos scholars, ou pelo menos por um grupo deles (formado por professores do Rio, Porto Alegre e São Paulo e entre os quais eu me incluía), da derrota de suas propostas no Congresso de Gramado, e que foi fundar uma revista (a revista Analytica, que existe até hoje) e, depois, uma sociedade filosófica de cunho estritamente acadêmico (a Sociedade Kant Brasileira), ambas com o mesmo propósito: contribuir para a formação de um público filosófico brasileiro e, mais amplamente, lusófono.

Vou focar nos objetivos da revista Analytica, não porque a considere mais importante que outras de seu gênero, igualmente importantes, mas porque eles (seus objetivos) tinham um viés especial que ressaltarei a seguir, a saber, a decisão de só publicar artigos em português, decisão essa que não parecia coerente com a visão acadêmica da Filosofia própria do scholar. Com efeito, implícita nessa maneira de ver está obviamente a ideia de que a Filosofia é um saber universal, donde resulta o reconhecimento da necessidade de integrar o estudo e a pesquisa no debate internacional. A questão, porém, era: como fazê-lo? Como integrar a pesquisa filosófica, que desejávamos fomentar no Brasil, no quadro da pesquisa feita no resto do mundo filosófico, e como fazêlo utilizando para isso exclusivamente a língua portuguesa?

A decisão parecia, à primeira vista, insustentável. Visto que o português é uma língua pouco conhecida e o inglês se tornou a lingua franca da ciência em nossa época, como o fora o latim na Idade Média, parecia imperativo usar o inglês tanto nas publicações quanto nos encontros internacionais, mesmo realizados no Brasil. Esta maneira de ver já era na época e ainda é a visão de muitos scholars brasileiros, notadamente aqueles ligados à lógica e à Filosofia analítica. É ela, por exemplo, que subjaz a publicações como a revista Manuscrito, fundada um pouco antes da revista Analytica.

Os fundadores da revista Analytica pensavam, porém, de uma maneira diferente e uma decisão diferente tomaram. Qual seja, a de só publicar artigos com um padrão de qualidade internacional, bem entendido, mas unicamente na língua portuguesa.

Pesaram na balança duas considerações. Primeiro, a importância que a linguagem natural tem para a Filosofia (mas não para a lógica e as ciências exatas, que usam uma linguagem matemática). Com efeito (era o que pensávamos), não só os conceitos temáticos da Filosofia são formulados linguisticamente, mas também os conceitos operatórios, inventados para o filósofo a fim de aclarar os conceitos que são o tema de sua reflexão, são 
formulados a partir de recursos fornecidos pela linguagem natural. Segundo, a importância do uso da língua portuguesa para a formação de um público filosófico no Brasil e nos países de língua portuguesa em geral (e, assim, para evitar que nossa inserção na discussão internacional se fizesse de maneira individual e periférica).

Não se tratava, convém notar, de dar um perfil brasileiro ao questionamento filosófico, muito menos de limitá-la a temas específicos da cultura brasileira (seguindo propostas de pensadores latino-americanos, como o mexicano Leopoldo Zea ou o argentino Henrique Dussel). Visto que a Filosofia era considerada por hipótese como voltada para temas universais, tratava-se simplesmente de criar um espaço em que os filósofos brasileiros pudessem dialogar entre si, para evitar que se tornassem apêndices isolados e distantes de uma discussão travada no essencial longe de nossas fronteiras.

Vinte anos após a publicação do primeiro número da revista Analytica, pode-se perguntar se foi acertada a decisão de só publicar artigos de qualidade internacional, mas em língua portuguesa. Se levarmos em conta os critérios institucionais para classificação das revistas filosóficas brasileiras, parece que não. Primeiro porque as revistas ditas internacionais (e isso significa na prática as que publicam preferencialmente em inglês) são ranqueadas em um nível acima das revistas nacionais, não importa a qualidade de seus artigos, pelo simples fato de publicarem em inglês. Segundo, porque os critérios para apoio dessas publicações são basicamente quantitativos, pois o que se exige delas (para fins de classificação e apoio) é uma certa quantidade de artigos publicados - e não o valor e a qualidade intrínseca de sua contribuição à pesquisa.

Eu quero argumentar aqui, no entanto, que a desvalorização da língua portuguesa como instrumento da pesquisa e da discussão filosófica repousa sobre pressupostos falsos.

Assim, acho, antes de mais nada, que a ideia de que o inglês tenha se tornado a lingua franca para a Filosofia, como o era o latim durante a Idade Média, precisa ser retificada. Com efeito, durante a Idade Média, o latim não concorria com nenhuma outra língua culta. Ora, isso contrasta não só com a Antiguidade greco-romana, na qual o grego veio a sofrer a concorrência do latim (graças aos esforços de Cícero e de Sêneca), mas sobretudo com os tempos atuais, em que o inglês sofre, não na ciência, é verdade, mas na Filosofia e nas humanidades em geral, a concorrência de outras línguas cultas, como o alemão e o francês. Por isso mesmo, não há razão válida para supor que outras línguas cultas, como é o caso do nosso português, bem como do espanhol e do italiano, não possam concorrer com o inglês, como instrumento da pesquisa 
filosófica. Mais ainda: no mundo globalizado que é o nosso a língua inglesa encontra certamente espaço para expandir o desejo de dominação cultural dos países anglo-saxônicos. Mas nele se encontra também, e talvez este seja o fato mais relevante, espaço para a exposição da diversidade cultural. $\mathrm{O}$ mundo cultural é um mundo em que as diferenças e particularidades nacionais se tornaram, sem jogo de palavras, particularmente visíveis. Qualquer um que frequente museus, bienais, feiras literárias tem disso uma demonstração $a d$ oculos, e não é razoável supor que o que ocorre nas artes contemporâneas não possa ocorrer no resto da cultura e, em especial, da Filosofia.

Por isso mesmo também acho que merece retificação a suposição de que a publicação em língua portuguesa nos condena à invisibilidade. A barreira da língua, certamente, ainda é alta, mas não impossível de ser aos poucos rebaixada, como indicam três fatos que gostaria de assinalar. Um deles é a publicação, por interesse e iniciativa da Sociedade Kant Norte-Americana, da tradução em língua inglesa de vinte artigos considerados representativos da pesquisa kantiana no Brasil. Os dois outros são menos notáveis, mas igualmente significativos. O primeiro é a referência, no número do início deste ano da revista alemã Information dedicado a um balanço da Filosofia nos últimos quarenta anos, à fundação da Sociedade Kant Brasileira e à disseminação dos estudos nietzschianos no Brasil. O segundo, o pedido de desculpas de Paul Guyer na Bibliografia de seu Companion sobre Kant e a Filosofia Moderna por não poder incluir nela livros e artigos em português, espanhol e italiano, onde se fazem atualmente, diz ele, importantes trabalhos de pesquisa.

Os sinais, como se pode ver, são contraditórios. Não sei para qual deles a nova geração filosófica vai atentar. Não sei nem mesmo se a Filosofia em língua portuguesa tem alguma chance de se impor no mundo que se diz globalizado. Não sei sequer se isso ainda é um projeto dos scholars brasileiros. Gostaria, porém, que os novos pensassem grande. Grande como o Brasil. 